\title{
Viewpoints
}

\section{Improving the interface between primary and secondary care: a statement from the European Working Party on Quality in Family Practice (EQuiP)}

\author{
O J Kvamme, F Olesen, M Samuelsson
}

\begin{abstract}
A group from the European Working Party on Quality in Family Practice (EQuiP), working with over 20 European colleges of primary care, has assessed what, in their view, is needed to improve the quality of care at the interface between general practice and specialists. Experiences and ideas from a wide range of people were gathered through focused group discussions. From these it was clear that, for real improvement at the interface of care, changes are needed in the system of care and in the ways that doctors view their roles and their performance. All providers of care need to be able to see the care system from the patients' perspective if they are to help their patients make sense of and benefit from an increasingly complex system. This paper outlines the EQuiP recommendations on how cooperation between general practitioners and specialists might be improved. This includes strategic perspectives and both targets for improvement and methods for teaching, training and development that are all independent of country and health care system. The 10 targets for development identified by the group are: leadership, initial shared care approaches, task division, mutual guidelines, patient perspective, informatics, education, team building, quality monitoring systems, and cost effectiveness. Working towards these targets could provide an effective approach to improving the cooperation between the interfaces of care. Getting effective leadership is a necessary first step as implementation of such a strategy will involve significant change. Responsibility lies primarily with the medical profession. (Quality in Health Care 2001;10:33-39)
\end{abstract}

Gepartment of University of Caen, 11 Rue Montebello, 30100 Cherbourg, France M Samuelsson, general practitioner

Correspondence to: Dr O J Kvamme oddkvamm@online.no

Accepted 18 December 2000
Keywords: quality improvement; primary health care; specialist health care

\section{Introduction}

As modern healthcare systems become more complicated and more people need coordinated care from both sides of the primary/ secondary interface, good communication between the sectors becomes a crucial factor in the delivery of good quality health care. However, the very complexity of health systems often mitigates against effective communication between the sectors. Improving the quality of cooperation, both between sectors and between professional groups, has not so far been a high priority in any of the European healthcare systems.

Much of the poor quality care can be linked to problems that arise at the interfaces within the healthcare systems. Many patients feel they are left "in limbo" when moving from one part of the system to another. ${ }^{1-4}$ Each part of the system tends to focus on its own tasks and resources and not on the system as a wholethat is, the system actually experienced by patients - so the task of improving the quality of interaction, cooperation, and communication across the interfaces is not seen as any one group's particular responsibility. Despite significant differences in their organisation, European health systems face similar problems with the cooperation between primary and secondary care. The solutions may also be similar.

General practitioners (GPs) and specialists have different roles and may often see problems from different perspectives: "In general practice, patients stay and diseases come and go. In hospitals, diseases stay and patients come and go." 5 The different perspectives and cultures and working conditions that exist within the medical profession reflect the wide range of medical, psychological, and social problems of the patients cared for by each group. Working in separate medical realities may diminish understanding and even respect for the concerns of others. Patients need the variety of expertise and technical competence. However, little effort has been devoted to bringing professional groups together to enable them to understand their roles and to make them feel their work is complementary with that of others within a single healthcare system. ${ }^{6}$ The pressure on doctors in all branches of medicine to respond to technological advances in their own specialties and to changes in patients' expectations diminishes opportunities to look beyond their separate worlds. 
Table 1 Perspectives of quality at the interface between GPs and specialists, with examples of tasks and actions to increase the quality of the interface

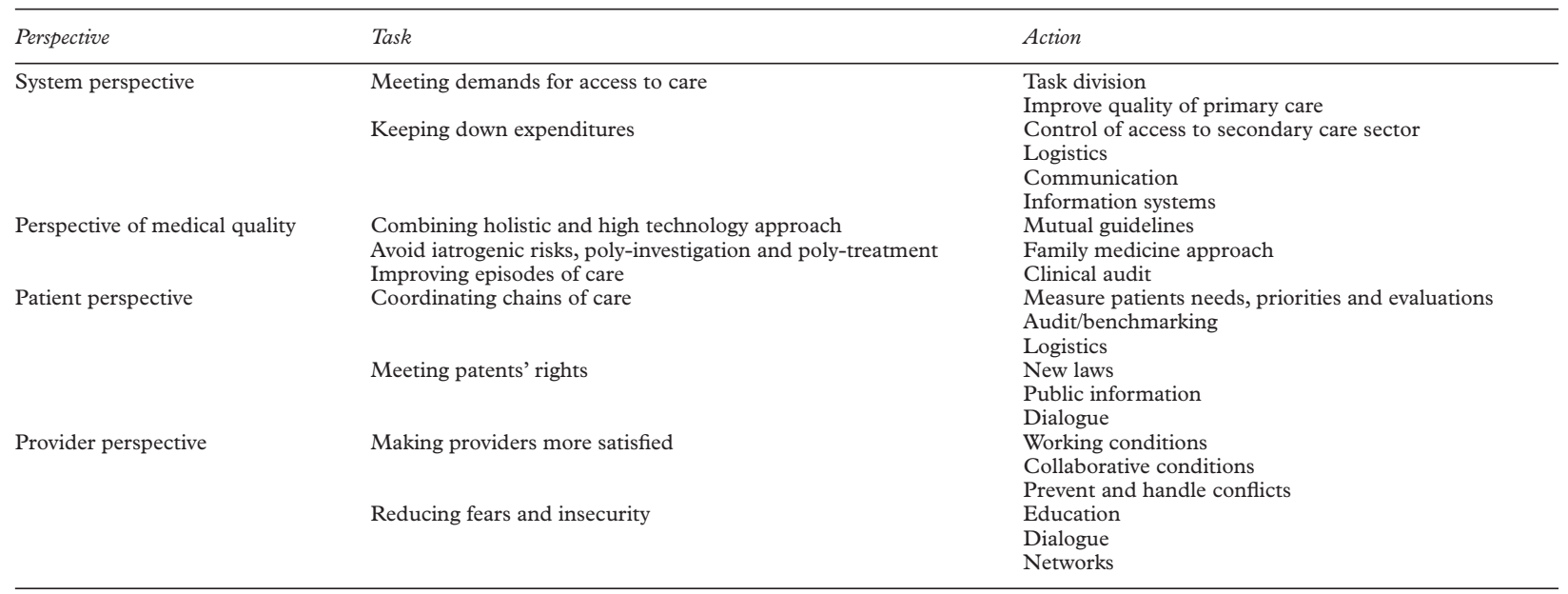

Shared care is one approach to improving care at the interface by minimising the apparent fragmentation of services. ${ }^{7}$ There is now a trend towards working in teams to solve complex technical or bio-psychosocial problems. The transfer of tasks between specialists and GPs is a natural and continuous process steered by technology, cost, and the needs of providers and patients.

Healthcare systems are examples of "competence systems" where the most important perceived asset is the ability and drive to create new knowledge. This is then transformed into effective interventions and disseminated throughout the system. However, the system is not uniform and there are large and significant variations in the quality of health care. The system does not function as a whole. Every organisation within the healthcare system needs to monitor, supervise, and improve the quality of structures, processes, and outcomes. In addition, both patients and society have a right to expect that there is a mechanism for quality of care to be looked at across the system as a whole and that someone is responsible for coordinating care processes across boundaries. This includes logistics, communication, and dissemination of information. Focusing on improving the functioning of the system as a whole may help to achieve the goal shared by many health systems to provide seamless care. It may also go some way to raising the overall quality of clinical care and improving patient satisfaction. $^{8}$

Finding ways of improving the quality of care at the primary/secondary care interface is an important objective of the European Working Party on Quality in Family Practice (EQuiP). Twice a year a working group meets to discuss strategies for improving care at the interface by collating ideas, activities, and experiences from a wide range of sources including over 20 European national colleges of primary care. For the last two years this group has explored the quality of care at the interface from four perspectives: (1) the system as a whole; (2) the delivery of good quality medical care; (3) the provider's viewpoint; and (4) the patient's viewpoint (table 1). Much of the information for this has been gained from focused group discussions. From this the working group has derived strategic targets and recommendations for quality improvement at the interface between primary and secondary care that should have relevance in European healthcare systems.

\section{Perspectives of the quality of care at the primary/secondary care interface} SYSTEM PERSPECTIVE

The demand for access to health technology is growing. A system approach to quality implies that we should understand and discuss division of tasks across boundaries within the system. Specialist time should, of course, be assigned to highly specialised duties, but the growing demand for specialised medical technology also requires that waiting times are acceptable in relation to need and that we also minimisethat is, do not use technological interventions inappropriately-society's expenditure on healthcare technology. ${ }^{9}$ If we view the system as a whole it is possible to see that changes in one part of the system can affect the patient and provider in another. It is our contention that at least some of the waste in resources might be avoided if care across the primary/secondary interface was improved through better communication and coordination.

\section{PERSPECTIVE OF MEDICAL QUALITY}

Every patient has the right to a discussion and interpretation of his or her symptoms within a holistic framework where all relevant biological, psychological, and social aspects of health can be considered. Patients also have the right to informed, up to date discussion about modern choices for investigation and intervention for any symptom. ${ }^{10}$ If we want to attain these two goals we need to make the best use of the specialism of family medicine/general practice care and all other medical specialties. To achieve this there has to be commitment to cooperation and understanding. The alternative - which is no longer acceptable-is fragmented and uncoordinated care. This is not only wasteful of resources but also places patients at the risk of poly-investigations, polyinterventions, and poly-pharmacy which are 
inevitably associated with a disjointed approach to care. All patients should be guaranteed access to a primary care physician appropriately skilled in diagnostics, treatment, and care who also refers appropriately those who need specialist attention.

\section{PATIENT PERSPECTIVE}

Patients expect a coordinated chain of investigation, treatment, and follow up. We need to understand better patients' views, expectations, and experiences of care within the system. The European Task Force on Quality in General Practice (EUROPEP) has developed an instrument validated to measure patients' evaluations of quality in general practice. ${ }^{11}$ Benchmarking between hospitals has been practised for many years and includes measures of patient perspectives. ${ }^{12}$ Patients are becoming increasingly knowledgeable and have access to much information about health care from many sources including the media and the internet. Moreover, the rights of patients are becoming secured in statutory frameworks. ${ }^{13}$

Patients' needs and expectations for care may clash, producing an "expectation gap", but this gap can be narrowed or closed by providing appropriate and timely information and by maintaining dialogue between the healthcare professions and the public and patients about their needs and the way in which the system works. ${ }^{14}$ The gap can also be narrowed by good professional cooperation at the interface between primary and secondary care. Good quality care always includes the appropriate use of biomedical skills and health technology together with the ability to help patients to cope with the fears and expectations of care. However, one practitioner may not possess all the necessary skills.

PROVIDER PERSPECTIVE

Satisfied workers provide good quality care and dissatisfied workers deliver care of a poorer quality. ${ }^{15} 16$ There needs to be capacity within the healthcare system to prevent and to settle conflicts between different specialties and professions to enable good working relations across all boundaries. Any competition between GPs and specialists should give way to an understanding of complementarity of function and of skills.

The increase in litigation in health care and the fear of law suits, exposure in the media, or penalties from official bodies may affect doctors' attitudes to clinical interventions. ${ }^{17}$ Such fears may lead to defensive medicine resulting in iatrogenic problems for patients, an increased workload and reduction in job satisfaction for providers, and a waste of resources for the system. A defensive approach diminishes equity of access to care and may reduce its quality. Continuous education and local networks can be used to make doctors feel more secure in their work, and could contribute to reducing defensive actions.
- Develop leadership with a defined responsibility for improving the interface

- Develop a shared care approach for patients treated in both primary and secondary care

- Create consensus on explicit task division and job sharing

- Develop guidelines that describe quality problems at the interface and seek solutions to such problems

- Develop an interface that contains the patient perspective

- Develop systems for appropriate information exchange to and from general practice care

- Reinforce interface improvement through education

- Facilitate team building across the interface

- Establish quality monitoring systems which focus on quality at the interface

- Establish a broad understanding of the need for cost effective use of the interface

Box 1 Ten targets for quality improvement at the interface between general practicelfamily medicine and specialist care.

Targets for quality improvement at the interface between GPs and specialists

Building on experiences and ideas from the perspectives chosen, the group identified 10 strategic targets for quality improvement at the interface between GPs and specialists that are universal to European healthcare systems. These targets are presented in box 1 and specific actions to each target are shown in table 2 .

DEVELOP LEADERSHIP WITH A DEFINED RESPONSIBILITY FOR IMPROVING THE INTERFACE For all healthcare systems the development of leadership is an important target for quality improvement at the primary/secondary care interface. This should involve regional administrators, local authorities, and healthcare professionals. Leaders need both to build effective teams and to delegate power and responsibilities if they are to promote really effective quality development. To improve the quality of care at the interface between primary and secondary care they must ensure that the job description of all providers includes consideration of how a professional cooperates with others, including those working in other sectors.

Facilitation of discussions on agreement between sectors and professions is the responsibility of leaders. These discussion should address incentives, barriers, strengths and weaknesses, and opportunities and threats to providing a good quality service. There should be incentives to encourage efficient and appropriate distribution of tasks and functions. Guidelines - owned by all who use them - are a likely consequence of such discussions.

Doctors must accept some limitations to their autonomy and work with their leaders. All healthcare professionals should learn about leadership. Professional leaders who have to gain consensus and encourage the system to 
Table 2 Actions to improve quality related to each of the EQuiP targets

\begin{tabular}{|c|c|}
\hline Target & Action \\
\hline Leadership & $\begin{array}{l}\text { Train professionals in leadership } \\
\text { Stimulate shared quality improvement processes } \\
\text { Define job descriptions clearly } \\
\text { Facilitate clinical guidelines across the interface } \\
\text { Facilitate guidelines for cooperation } \\
\text { Facilitate consensus discussions }\end{array}$ \\
\hline Shared care approach & $\begin{array}{l}\text { Stimulate communication across the interface } \\
\text { Involve local leadership in quality improvement } \\
\text { Audit care across the interface } \\
\text { Create dialogue with patients }\end{array}$ \\
\hline Consensus on task division & $\begin{array}{l}\text { Establish discussion groups with GPs, specialists and leaders } \\
\text { Strengthen the professional identity of GPs } \\
\text { Base solutions on needs and resources in each country }\end{array}$ \\
\hline Guidelines & $\begin{array}{l}\text { Local GPs and specialists establish local guidelines together } \\
\text { Guidelines must include consensus on cooperation between GPs and specialists } \\
\text { Patient perspective to be included in guidelines }\end{array}$ \\
\hline Patients & $\begin{array}{l}\text { Audit patient "journeys" across interfaces and through the health care system } \\
\text { Include patients in audit } \\
\text { Monitor patient expectations and evaluation of care by validated methods }\end{array}$ \\
\hline Information & $\begin{array}{l}\text { Electronic patient records, guidelines and recommendations } \\
\text { Electronic communication and transfer of information across the interface } \\
\text { Public information about access, processes, and outcomes }\end{array}$ \\
\hline Education & $\begin{array}{l}\text { Basic medical education to include courses in quality improvement } \\
\text { Specialist vocational training in general practice care sector } \\
\text { Joint CME courses for specialists and GPs }\end{array}$ \\
\hline Team building & $\begin{array}{l}\text { Teams defined by tasks and circumstances } \\
\text { "Interface teams" for specific groups of patient, e.g. palliation, rehabilitation of stroke } \\
\text { patients, diabetic care }\end{array}$ \\
\hline Monitoring quality in clinical work & $\begin{array}{l}\text { Audit, benchmarking, patient surveys } \\
\text { Monitor outcomes and processes } \\
\text { Use indicators selected in guidelines }\end{array}$ \\
\hline Cost effectiveness & $\begin{array}{l}\text { Is a result of QI, not a prime target } \\
\text { Select indicators that cover both primary and secondary care }\end{array}$ \\
\hline
\end{tabular}

$\mathrm{CME}=$ continuing medical education; $\mathrm{QI}=$ quality improvement.

work as a whole are part of a modern health service. They should be willing to communicate outside their clinical practice with, for example, other leaders, politicians and economists, and to enter into a wider debate about ways of improving the quality of care throughout the system.

DEVELOP A SHARED CARE APPROACH FOR PATIENTS TREATED IN BOTH PRIMARY AND SECONDARY CARE

For shared care to be implemented the barriers between different parts of the healthcare system must go. Accomplishing this will depend on stimulating effective cooperation across interfaces and on the development of local management structures designed to encourage rather than impede the process of care across the boundaries. Care needs to be seen from the patients' perspective and managed, for example, by the development of guidelines which include processes that match the patients' perspective and descriptions of the distribution of tasks between primary and secondary care.

An important precondition to implementing effective shared care is that all those involved cooperate and have shared goals that are explicit. The creation of comprehensive guidelines and the development of logistics for increasing patient and public access to information may increase the rate of acceptance of shared care and help to initiate processes instrumental in achieving it. Providers and managers leading change should communicate with patients and their representatives and also with politicians. Improving the quality of the system of care needs to be a common aim understood by all who use, work in, or influence care across the interface between primary and secondary care.

CREATE CONSENSUS ON EXPLICIT TASK DIVISION AND JOB SHARING

Distribution of tasks between specialists and GPs should not imply that all technical problems are for the specialist and the rest for the GP. GPs work within an expanded biological, psychological, and social model. While much of their work integrates the relevant aspects of patients' reactions, coping strategies, empowerment strategies, and social context, parts of their work are also simply technical. Treatment of a clinical problem should be at the optimal level of care-for the patient and for the system - and this is often in primary care.

Some countries are still struggling to define the identity and content of general practice within their healthcare systems. Difficulties are encountered with drawing the lines between primary and secondary care in general, and between GPs and specialists in particular. In some countries the lack of professional identity of GPs makes it difficult to agree upon task division and shared care. These difficulties will only be overcome with effective medical leadership.

Discussions about the content of general and specialist practice should be based on national needs and provision but, in all systems, it should be guided by the aims of creating equity, accessibility, and cost effective care. Again, effective medical leadership will be necessary to facilitate discussions to define the roles and functions. Better cooperation is likely to be accompanied by a change in attitude from "mine" and "your" patients or tasks to "ours". 
DEVELOP GUIDELINES THAT DESCRIBE QUALITY PROBLEMS AT THE INTERFACE AND SEEK

SOLUTIONS OF SUCH PROBLEMS

Guidelines should be based on up to date information and set within national and local possibilities, cultures, and traditions. They should address the use of appropriate technology, cost effective care, and actions that ensure equity and accessibility with the maximum of patient and provider satisfaction. Centrally developed national clinical guidelines, built on evidence based medicine, are comprehensive and resource demanding. Guidelines need to be adapted to the local context and reflect the available human, structural, and economic resources. They should be developed from a multidisciplinary point of view and should include task distribution and act as an exchange of information about care at the primary/secondary interface. Guidelines should include intended indicators of the quality of the care. Leaders should use the groups that develop and monitor guidelines to help foster better work across the primary/ secondary interface, as GPs and specialists in these groups may already have developed positive working cooperative relationships.

DEVELOP AN INTERFACE THAT CONTAINS THE PATIENT PERSPECTIVE

The patient should experience a seamless healthcare system and, as far as possible, continuity of care. We must focus organisation of care around an understanding of "patient flow" and "patient journeys" and make more use of logistics to improve the quality of the patient's experience across the system.

Patients or their representatives should be included in planning and auditing shared care on an equal basis with professionals and managers to ensure that their needs are considered. Patients' views should be included during guideline development and their representatives may be members of guideline groups. Professionals and their leaders have an obligation not only to take account of the views expressed by patients and their representatives, but also to stimulate and encourage patients to express their opinions. The inclusion of patients' views could lead to improved adherence to care plans and a better understanding of equity which might help to get medical priorities right.

DEVELOP SYSTEMS FOR APPROPRIATE

INFORMATION EXCHANGE TO AND FROM GENERAL PRACTICE

Information about health care comes from many sources. Enabling as many people as possible to have easy access to information about health and health care is an important priority. The only exception to this is, of course, the "case based" information about individual care. Information that should be available includes "disease based" information (clinical guidelines), "educational" information to the public (for example, about healthy eating and healthy lifestyles), and "quality" information about practices and hospitals (availability, service, outcomes). All such information should meet standards of accuracy, timeliness, availability, and clarity. Getting it out in a format that meets the needs of providers and the public will require the use of modern informatics, but many health services remain woefully behind in the development and implementation of information technology. Models for sharing information within the context of genuine effective formats need to be designed and adapted to local conditions, and the input of both GPs and hospital specialists is needed. The potential of the internet and intranet facilities as sources of information and means of communication is enormous. The development of informatics should be a high priority for research and development.

\section{REINFORCE INTERFACE IMPROVEMENT THROUGH} EDUCATION

The competence and skills necessary for clinical practice are learnt in basic education programmes and should be reinforced and developed through continuing medical education (CME). Interestingly, as far as we have been able to determine, basic medical education programmes do not include any training in quality improvement. This may go some way to explaining the difficulties of sustaining coordinated care. Vocational training, programmes for $\mathrm{CME}$ and, in particular, programmes for continuous professional development (CPD) could be used as the focus for introducing practitioners to the theory and for training in the skills needed for quality improvement. Redesigning CME and CPD to reflect a shift towards more shared care will take effort and will certainly involve the creation of joint programmes by the different specialties.

More fundamentally, the educational system should encourage the development of cooperation skills within basic medical education, training in a culture of mutual respect for shared care thinking, task distribution, and respect of patients' expectations of high quality seamless care. All postgraduate programmes should include time in both general practice and specialist practice. This demands more balanced curricula that widen the perspective of participants so that all have some understanding of biological, psychological, and social perspectives and an appreciation of concerns relevant to the world of high technology interventions.

Specialist training schemes should encourage development of insight into the concerns of a range of other specialties. Doctors undergoing specialist training should experience working across the interfaces. Currently, specialists spend little or no time in family medicine during their training, although GPs are extensively trained in hospitals. Specialists should be trained in the patterns of diseases, signs, and symptoms within the primary healthcare system as well as in those presenting to specialist practice. All trainees should have appropriate training and insight into possible organisational problems at the primary/secondary care interface from the perspectives of both patients and 
providers. The lack of balance in current educational systems limits the understanding of care at the interface.

FACILITATE TEAM BUILDING ACROSS THE

INTERFACE

Functioning, effective, and coherent teams do not just "happen". They require work, but there is a large literature on team working and team building that is easily available. Professionals need to draw on this when setting up teams to deliver shared care training programmes for "quality team work". Teams should review and evaluate the quality of their work and change their practice when indicated. New innovations in health care and the development of current techniques means that, with time, tasks will change or will be shifted between professionals within a team. For instance, registered nurses now perform tasks that previously were strictly the responsibilities of doctors. Rehabilitation programmes extend across the interface between hospital and primary care and involve several professional groups. Thus, new teams are formed by tasks and by circumstances. While team building and cooperation are essential for the functioning of a seamless system of care, patients also ask for personal care and continuity of care. Well functioning teams that serve the system must also ensure a maximum of personal care.

ESTABLISH QUALITY MONITORING SYSTEMS WHICH FOCUS ON QUALITY OF THE INTERFACE Quality of care may be evaluated in terms of process and of outcomes. Both need to be measured for care that crosses the interface. Developing indicators that measure the quality of cooperation and communication at the interface of care is an important area of research. ${ }^{18}$ The gap between patients' expectations of care and the care that they actually receive is a possible indicator or "proxy" for the quality of care at the interface. It is a central element of cooperation, it is measurable through patients' and professionals' evaluations, and is universal with respect to different healthcare systems. Other indicators that could be used include measures of the continuity of care, of coordination of care processes, and the quality and consistency of the information given to patients. Research is needed to define the most appropriate indicators of the quality of care. Leaders of improvement in care should be responsible for including effective systems for the quality of care as part of any change process.

ESTABLISH A BROAD UNDERSTANDING AT THE INTERFACES OF CARE OF THE NEED FOR COST EFFECTIVENESS

In societies where there is a large gap between the resources available and the sophistication of technological possibilities, a drive to cost effectiveness may help to achieve an equitable distribution of healthcare services. Concentrating on cost effective interventions will improve the likelihood of providing equal and sufficient access for all citizens with equal needs. Ensuring cost effectiveness of working processes is a major element of any effort to improve the quality of care at the interface. Quality improvement may be considered an investment that leads over time to more cost effective and efficient health care. ${ }^{19}$

An important and probably cost effective outcome of improving care at the interface would be to increase the frequency at which patients receive the right care (and nothing more) at the right level, at the first try. This would minimise work and costs. Better information and coordination at the interface between primary and secondary care are necessary prerequisites to achieving this goal and, importantly, all those working in the system will need to understand the system from the perspectives of others.

\section{Conclusions}

An action plan with 10 targets for improving the quality of care across the primary/ secondary care interface has been set out. Actions necessary for achieving each of the 10 targets are given in table 2 . The work required in different countries will be based on national needs, priorities, and resources. The suggestions are not in any way mandatory, but are set to stimulate discussion about the quality of care across the interface between GPs and specialists. It is not within the scope of this article to deliver detailed plans for quality improvement within a system because such actions must be developed and performed by those working in the system.

It is the purpose of EQuiP to encourage professional organisations and leaders of healthcare systems throughout Europe to discuss these targets and to adapt the principles to their national setting. Whilst national plans for action will differ, EQuiP wants to encourage leaders to use specified indicators within quality improvement and medical performance assessments that allow benchmarking and comparisons of progress between centres.

The group recommends that particular attention is paid to the following three areas when implementing a strategy for quality improvement across the primary/secondary care interface:

- Improvement in leadership is probably the most important task for the implementation of effective shared care. It is the responsibility of both clinicians and managers to develop leaders capable of leading their colleagues to work in a way that promotes quality improvement.

- Bringing GPs and specialists together and developing personal and group relations through education and processes of task sharing is a powerful instrument of change. The Danish model for GPs as advisors in hospitals is a multipotential method of promoting cooperation between GPs and specialists. GPs acting as "facilitators" of cooperation may assist the creation of shared care, the initiation and promotion of clinical guidelines for shared care, and the formation of new information channels across the interfaces. ${ }^{6}$

- Bridging the expectation gap by empowerment of patients can improve the experiences of 
patients and professionals. Patients will share their views and may carry their part of the common responsibilities to improve quality of the interface. It is the responsibility of the patients, when given the opportunity, to express their expectations and experiences to providers and leaders of health care. Political initiatives and better cooperation between professionals, politicians, and healthcare leaders may be needed to change the culture of health care to achieve this.

Working towards the 10 targets set out by EQuiP should direct the attention of leaders within the medical profession to the importance of making sure that the healthcare system works as a whole and that care for individual patients does not fall down because of poor coordination and cooperation at the interfaces. By doing so, we should achieve a situation where the health system is redesigned to enable care to be delivered by doctors committed to quality improvement across the whole service, cooperating to provide care that is perceived by patients as seamless. ${ }^{17}$

This paper is written on behalf of the EQuiP working group on interface problems in health care. The members of the working group are: Vivian Alles (Estonia), Michael Boland (Ireland), Poul Brix Jensen (Denmark), Hans Joachim Fuchs (Austria), Gunnar Gudmundsson (Iceland), Odd Jarle Kvamme (Norway), Frede Olesen (Denmark), Jose M Bueno Ortiz (Spain), Leif Persson (Sweden), Marianne Samuelsson (France), Perrti Soveri (Finland), and Tomasz Tomasik (Poland).

1 Mainz J. Problem identification and quality assessment in health care: theory, methods and results (Danish). København: Munksgaard, 1995.
2 Roland $M$, ed. $R \mathcal{E} D$ priorities in relation to the interface Roland $\mathrm{M}$, ed. $R \mathcal{E} D$ priorities in relation to the interface
between primary and secondary care. Report to the Central Research and Development Committee. Leicester: Department of Health, 1995.

3 Dahler-Eriksen K, Lassen JF, Olesen F, et al. Clinical guidelines across sectors: an example of a co-operating health care system (Danish). Ugeskrift Loger 1998;35:5021-4.

4 Preston C, Cheater F, Baker R, et al. Left in limbo: patients' views on care processes across the primary/secondary interface. Quality in Health Care 1999;8:16-21.

5 Heath I. Commentary: the perils of checklist medicine. BMf 1995;311:373.

6 Olesen F. General practitioners as advisors and coordinators in hospitals. Quality in Health Care 1998;7:42-7.

7 Øvretveit J. Integrated quality development in public health care. Continuing education and quality improvement. Oslo: The Norwegian Medical Association, 1999.

8 Berwick D. Medical associations: guilds or leaders? BMF 1997;314:1564.

9 Olesen F, Fleming D. Patient registration and controlled access to secondary care. Eur f Gen Pract 1998;4:81-3.

10 Olesen F, Mainz J. Research, technology assessment and quality assurance. Eur f Gen Pract 1996;2:162-5.

11 Grol R, Wensing M, Mainz J, et al. Patients' priorities with respect to general practice care: an international comparison. European Task Force on Patient Evaluations of General Practice. Family Pract 1999;16:4-11.

12 Kopp VJ. Preoperative preparation. Value, perspective, and practice in patient care. Anesthesiol Clin North Am 2000;18: 551-74.

13 NHS Management Executive. The patient's charter and primary health care. London: Department of Health, 1992.

14 Smith JA, Scammon DL, Beck SL. Using patient focus groups for new patient services. Ft Comm f Quality Improvement 1995;21:22-31

15 Clampitt P. Employee perceptions of the relationship between communication and productivity. F Business Comm 1999;30:5-28.

16 Albrow M, Sira I, Studio OR. Do organisations have feelings? Organisational Studies 1992;13:313-29.

17 Dickson G. Principles of risk management. Quality in Health Care 1995;4:75-9.

18 Lawrence M, Olesen F. Indicators of quality in health care. Eur f Gen Pract 1997;3:103-8.

19 Hampson JP, Roberts RI, Morgan DA. Shared care: a review of the literature. Family Pract 1996;13:264-79.

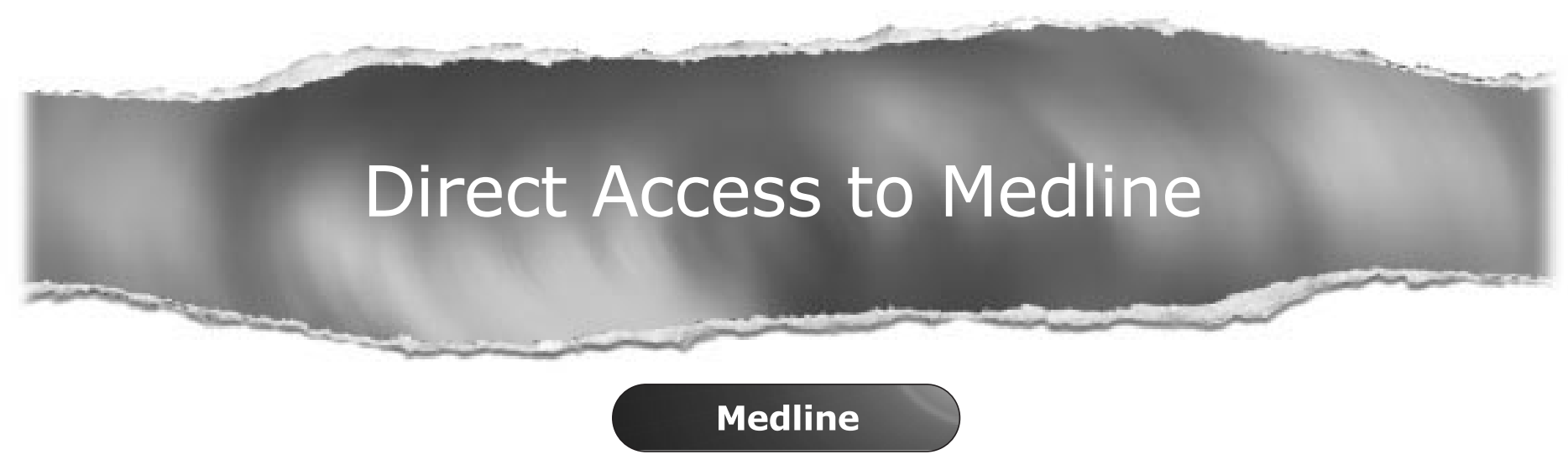

Link to Medline from the homepage and get straight into the National Library of Medicine's premier bibliographic database. Medline allows you to search across 9 million records of bibliographic citations and author abstracts from approximately 3,900 current biomedical journals.

www.qualityhealthcare.com 


\section{BOOK REVIEWS}

The Healthcare Quality Handbook: A Professional Resource and Study Guide. 15th Annual Edition. Janet A Brown. (Pp 800; $\$ 125$ for NAHQ members, $\$ 140$ for non-members, yearly updates available for additional fee). California: Managed Care Consultants, 2000. (Also available through the National Association for Healthcare Quality (NAHQ), P O Box 3781, Oakbrook, Illinois 60522, USA.)

Revised yearly since 1986 , this is an 800 page loose leaf handbook in a ring binder and is used by some readers to prepare for the International Certified Professional in Healthcare Quality (CPHQ) examination of the Healthcare Quality Certification Board which is associated with the National Association for Health Quality (NAHQ).

Imagine a classmate of yours known for taking meticulous notes for all her classes and homework. Imagine that she kept such notes for the equivalent of a master's degree in health care quality and she kept reading and updating these notes for 15 years. This may give you an idea of what Janet Brown has written. The result is a book too heavy to hold in your hands for long. There are lots of definitions, lists, and bullet points summarising the literature. These references are cited. Brown's outline approach allows a lot of densely packed information to be included; there are proportionally few full paragraphs. Three hundred and fifty multiple choice questions are included to test your knowledge and prepare for the CPHQ examination.

About $20 \%$ of the content is specific to laws and institutions in the USA such as the requirements of the Joint Commission on the Accreditation of Healthcare Organizations (JCAHO). Some of this may be of interest to experts outside the USA. The other $80 \%$ is quality theory and principles and is applicable anywhere.

The book is divided into sections on quality concepts, strategic leadership, quality system management, performance improvement, information management, people management, and USA federal legislation related to quality. Here is a haphazard sampling of concepts to be found in the book: factors affecting utilisation, Deming's 14 points, risk management, benchmarking, team leadership skills, clinical pathways, case management, medical records review, medical staff appointment process, quality indicators, the European Foundation for Quality Management award criteria, affinity diagrams, the "five whys", FOCUS-PDCA, and the list goes on. The density of information in this practical handbook is such that it makes any other book on health care quality published in the last decade seem undernourished and anaemic. The most similar book known to this reviewer is the 778 page textbook by Goetsch and David entitled Quality Management: Introduction to Total Quality Management for Production, Processing and Service, 3rd edition, published in 2000 by Prentice Hall. This is a basic general class room textbook for management students and is a companion more than a competitor to Brown's handbook.
In a personal communication with Janet Maronde, Executive Director of the Healthcare Quality Certification Board, she informed me that since 1984 the CPHQ examination has been taken by 13000 people and 9500 have been certified. For the first time in the year 2000 it has become international. It is given in many locations around the world and the content specific to the USA has been nearly eliminated. Maronde was careful to say that her Board does not recommend any particular textbook to prepare for the CPHQ examination, but that many people use Janet Brown's handbook for this purpose.

No errors of commission were found in the handbook. Although the pages are not numbered, the chapters and paragraphs are. This, and the lack of an index, make inserted revisions easier. Given the size and density of the handbook, it seems unfair to ask for more. This reviewer would like to have seen more on statistical process control. Perhaps European readers would like more on ISO 9000 and its updates, even though this approach is not widely used in USA health care. The section on reduction in medical errors will no doubt be expanded in future revisions, but this literature in health care is just beginning.

This unique handbook should be available to every health care quality professional who wishes to recognise and have access to the large body of ideas and methods now available for improvement. It should become available on computer disk in the future.

\section{NEUHAUSER}

Case Western Reserve University, Cleveland, Ohio 44106-4945, USA

Medical Humanities David Greaves, Martyn Evans, Editors. Published twice yearly in June and December as a special edition of the fournal of Medical Ethics. Personal subscription: $£ 21.00$ (US\$33.00). London: BMJ Publishing Group.

The template is Chekhov. Or maybe the patron saint. Call him the lode star, anyway, for those who want to bring medicine and the humanities together.

Picture the scene. There he is, late one night, any night, deep into The Three Sisters, or Uncle Vanya, or The Seagull and there's a knock at the door which, opened up by the housekeeper, reveals a scruffy urchin who says those magic words "Can the doctor come...?"

And so Chekhov the writer lays down his pen and drags himself away from the Prozorov's drawing room, or Vanya's office, or Arkadin's dining table, and rises from his desk. And Chekhov the doctor goes out into the night. It's a story to strike shame in the heart of any precious writer, trust me. Chekhov, naturally enough, figures in the first issue of Medical Humanities. A paper on Chekhov's short story $A$ Case History considers, among other things, the polyphonic nature of doctor-patient communications-a perfect example of how naturally fiction and medicine fuse together. Just how inherently dramatic is the business of medicine is something instantly recognisable to the novelistnot in the sense of ER or Casualty in which medicine and all things medical, including its practitioners, provide merely an exciting and glamorous location and justification for the drama-but in the manner, for instance, in which director Peter Brook uses it in his work with Oliver Sacks, or American doctor/writer Frank Huyler in his wonderful Blood of Strangers, a review of which, incidentally, also appears in the journal.

There's plenty to fascinate the novelist in this new journal-interesting ideas on sickness or health and, of course, Chekhov. As a writer in residence at a medical school I found papers on the relationship between arts and medicine, and its current state of play in medical schools, invaluable.

What is more interesting, though, is that, to someone on the humanities side, there appears to be something unnecessarily deferential about the approach medicine makes to the arts, like poor old peasant-stock Lopahin, capin-hand, before he bought the cherry orchard.

Imagine this if you can. A bunch of English Literature lecturers, concerned about the teaching of the subject in the country's universities, in particular the sort of narrow visioned students, lecturers, novels, plays, etc it is producing, decide to introduce a Special Study Module in Science and Medicine into the degree. Difficult isn't it?

Roll on the well rounded doctor. Let's hope and pray, for all our sakes, they don't start requiring the same of writers.

CAROL CLEWLOW Writer in Residence, Department of Epidemiology \& Public Health, School of Health Sciences, The Medical School, University of Newcastle, Newcastle upon Tyne NE2 4HH, UK

\section{Corrections}

\section{DARTS study}

In the Viewpoint article entitled "The potential use of decision analysis to support shared decision making in the face of uncertainty: the example of atrial fibrillation and warfarin anticoagulation" by A Robinson and R G Thomson on behalf of the Decision Analysis in Routine Treatment Study (DARTS) team which appeared on page 238 of the December 2000 issue of Quality in Health Care, the following acknowledgement should have appeared: "The DARTS project was commissioned by the West Midlands Regional NHS Executive R\&D programme and Eli Lilly Ltd". The authors apologise for this omission.

\section{EQuiP statement}

In the Viewpoint article entitled "Improving the interface between primary and secondary care: a statement from the European Working Party on Quality in Family Practice (EQuiP)" by O J Kvamme et al which appeared on page 33 of the March 2001 issue of Quality in Health Care, the name of the last author was incorrectly spelt. The correct spelling is $M$ Samuelson. The publishers apologise for this error 